\title{
Relationship between disease severity and quality of life in patients with chronic obstructive pulmonary disease
}

\author{
F.F. Sanchez ${ }^{1,2}$, M.M. Faganello ${ }^{3}$, S.E. Tanni ${ }^{4}$, P.A. Lucheta ${ }^{4}$, C.R. Padovani ${ }^{5}$ and \\ I. Godoy ${ }^{4}$ \\ 1Departamento de Fisioterapia, Centro Universitário Católico Salesiano Auxilium (Unisalesiano), \\ Araçatuba, SP, Brasil \\ ${ }^{2}$ Faculdades Adamantinenses Integradas, Adamantina, SP, Brasil \\ ${ }^{3}$ Departamento de Fisioterapia, Unisalesiano de Lins, Lins, SP, Brasil \\ ${ }^{4}$ Departamento de Medicina Interna, Faculdade de Medicina de Botucatu, ${ }^{5}$ Departamento de \\ Bioestatística, Instistuto de Biociências, Universidade Estadual Paulista, Botucatu, SP, Brasil \\ Correspondence to: F.F. Sanchez, Rua Liberdade, 797, 16200-170 Birigui, SP, Brasil \\ Fax: +55-18-3636-5252. E-mail: fersanchez1@hotmail.com
}

\begin{abstract}
Few studies have evaluated the relationship between Airways Questionnaire 20 (AQ20), a measure of the quality of life, scores and physiological outcomes or with systemic markers of disease in patients with chronic obstructive pulmonary disease (COPD). The aim of the present study was to investigate the relationship of forced expiratory volume in $1 \mathrm{~s}\left(\mathrm{FEV} \mathrm{V}_{1}\right)$, body mass index, fatfree mass index, 6-min walk test $(6 \mathrm{MWT})$ results, dyspnea sensation and peripheral oxygen saturation $\left(\mathrm{SpO}_{2}\right)$ with the quality of life of COPD patients. Ninety-nine patients with COPD (mean age: $64.2 \pm 9.2$ years; mean FEV : $_{1} 60.4 \pm 25.2 \%$ of predicted) were evaluated using spirometry, body composition measurement and the 6MWT. The baseline dyspnea index (BDI) and the Modified Medical Research Council (MMRC) scale were used to quantify dyspnea. Quality of life was assessed using the AQ20 and the St. George's Respiratory Questionnaire (SGRQ). The Charlson index was used to determine comorbidity. The body mass index/airflow obstruction/dyspnea/exercise capacity (BODE) index was also calculated. AQ20 and SGRQ scores correlated significantly with $\mathrm{FEV}_{1}, \mathrm{SpO}_{2}, 6 \mathrm{MWT}, \mathrm{MMRC}$ and $\mathrm{BDI}$ values as did with BODE index. In the multivariate analyses, MMRC or BDI were identified as predictors of $A Q 20$ and SGRQ scores $(P<0.001$ in all cases). Thus, the relationship between $A Q 20$ and disease severity is similar to that described for SGRQ. Therefore, the AQ20, a simple and brief instrument, can be very useful to evaluate the general impact of disease when the time allotted for measurement of the quality of life is limited.
\end{abstract}

Key words: Pulmonary disease; Chronic obstructive pulmonary disease; St. George's Respiratory Questionnaire; Airways Questionnaire 20; Respiratory system

Research supported by FAPESP (\#04/00517-4). F.F. Sanchez is the recipient of a scholarship from CAPES.

Received October 30, 2007. Accepted September 24, 2008

\section{Introduction}

The assessment of health-related quality of life is an important tool for determining the impact of disease severity in patients with chronic obstructive pulmonary disease (COPD) and for monitoring their response to treatment (1). A recent study showed that health status was significantly predictive of mortality in COPD patients, independent of airflow limitation and age (2).
The St. George's Respiratory Questionnaire (SGRQ) and the Airways Questionnaire 20 (AQ20) are examples of specific instruments used for the assessment of quality of life in patients with lung diseases $(3,4)$. The average time to complete and score the SGRQ is estimated to be 10-13 min, compared with 3-4 min for the AQ20 $(3,5)$. Since it is short and can be quickly completed and scored, the AQ20 could be a useful instrument in situations when the time allotted for quality of life assessments is limited. 
Various studies have evaluated the relationship between SGRQ scores and physiological outcomes, as well as between SGRQ scores and systemic markers of COPD. It has been shown that forced expiratory volume in $1 \mathrm{~s}\left(\mathrm{FEV}_{1}\right)$, nutritional status and the 6-min walk test (6MWT) distance present weak correlations with SGRQ scores in COPD patients (6-10). However, various investigators have reported a strong relationship between dyspnea and SGRQ scores, performing multiple regression analyses in which dyspnea was identified as the greatest contributing factor to variations in questionnaire scores in patients with COPD (6,8-11).

The discriminatory power and responsiveness of the AQ20 in comparison with the SGRQ was first established by Hajiro et al. (12) in a study involving 165 patients with stable COPD. However, few studies have evaluated physiological outcomes and systemic markers of COPD in relation to quality of life as assessed using the AQ20 in COPD patients $(3,5,12)$. Therefore, the aim of the present study was to determine the relationship of $\mathrm{FEV}_{1}$, body mass index (BMI), fat-free mass index (FFMI), 6MWT results, dyspnea sensation and peripheral oxygen saturation $\left(\mathrm{SpO}_{2}\right)$ with the AQ20 scores in a cohort of COPD patients.

\section{Patients and Methods}

Between August 2004 and August 2005, 99 COPD patients, consecutively recruited from an outpatient clinic, were evaluated. Patients were included if they met the criteria for COPD according to the guidelines established in the global initiative for chronic obstructive lung disease (13): a post-bronchodilator $\mathrm{FEV}_{1}$ /forced vital capacity (FVC) ratio $<0.70$, and an increase in $\mathrm{FEV}_{1}$ after inhalation of a $\beta_{2}$ agonist $<15 \%$ or $200 \mathrm{~mL}$. Additional inclusion criteria were as follows: being clinically stable, having no history of infections or exacerbation of respiratory symptoms or changed medication within the 2 months preceding the study onset, and presenting no clinical signs of edema. The following exclusion criteria were applied: inability to perform the lung function tests and 6MWT, inability to understand or complete quality of life questionnaires, myocardial infarction within the preceding 4 months, unstable angina, and congestive heart failure (New York Heart Association class II or IV). All patients were made aware of the proposed study procedures and freely gave written informed consent. All procedures were approved by the Research Ethics Committee of the Universidade Estadual Paulista (UNESP), School of Medicine at Botucatu, in the State of São Paulo, Brazil.

Pulmonary function and peripheral oxygen saturation Pulmonary function and reversibility tests were per- formed using a spirometer (Ferraris KOKO, USA) according to the criteria established by the American Thoracic Society (14). Values of $\mathrm{FEV}_{1}$ are reported in liters, in percent of FVC and as percent of reference values (15). $\mathrm{SpO}_{2}$ was evaluated using an oximeter (Onyx 9500; Nonin Medical, USA).

\section{Nutritional assessment}

Body weight and height were measured. BMI (weight/ height $^{2}$ ) was also calculated. Body composition was evaluated using a bioelectrical impedance analyzer (BIA 101A; RJL systems, USA). Resistance was measured on the right side of the body with the patient in the supine position in accordance with the European Society for Clinical Nutrition and Metabolism (ESPEN) guidelines (16). Fat-free mass (FFM) was estimated (in $\mathrm{kg}$ ) using a group-specific regression equation developed by Kyle et al. (17), and the FFMI was also calculated (expressed as FFM/height ${ }^{2}$ ). The muscle depletion criteria used was FFMI $\leq 16 \mathrm{~kg} / \mathrm{m}^{2}$ (for men) or $\leq 15 \mathrm{~kg} / \mathrm{m}^{2}$ (for women) (18).

\section{Quality of life and baseline dyspnea}

Translated versions of the SGRQ and AQ20, both validated for use in Brazil $(3,19)$, were used to evaluate quality of life. Translated versions of the baseline dyspnea index (BDI) $(20,21)$ and of the Modified Medical Research Council (MMRC) dyspnea scale were used to evaluate the degree of dyspnea $(22,23)$.

\section{Six-minute walk test}

The 6MWT was performed according to the American Thoracic Society guidelines (24). Patients were instructed to walk, attempting to cover as much ground as possible within $6 \mathrm{~min}$. A research assistant timed the walk, and standardized verbal encouragement was given. Patient $\mathrm{SpO}_{2}$ was monitored throughout the test. Patients who were hypoxic at baseline and patients whose $\mathrm{SpO}_{2}$ decreased to $<85 \%$ during the test were given oxygen by a physical therapist who wheeled an oxygen tank in a handcart alongside the patient. Before and after the test, data were obtained for $\mathrm{SpO}_{2}$, heart rate, respiratory rate, dyspnea sensation (Borg scale dyspnea score) and blood pressure. The distance covered is reported in meters.

\section{BODE index and comorbidity index}

For the calculation of the BMI/airflow obstruction/dyspnea/exercise capacity (BODE) index, we used the model of Celli et al. (25). For each threshold value of $F_{E V}, 6 M W T$ distance, and MMRC dyspnea grade, the patients received points ranging from 0 (lowest value) to 3 (maximal value). For $\mathrm{BMI}$, the values were $1\left(\mathrm{BMI} \leq 21 \mathrm{~kg} / \mathrm{m}^{2}\right)$ or 0 
$\left(\mathrm{BMI}>21 \mathrm{~kg} / \mathrm{m}^{2}\right)$. The points of each variable were added so the BODE index ranged from 0 to 10 points for each patient. The Charlson index was used to determine the degree of comorbidity (26).

\section{Statistical analysis}

Results are reported as mean \pm SD unless otherwise indicated. Correlations between variables were assessed using Spearman's rank order correlation. Multiple linear regression analysis was performed using SGRQ and AQ20 scores as dependent variables. Variables significantly associated with quality of life score or included in the BODE index ( $\mathrm{FEV}_{1}$, BMI, 6MWT distance, MMRC grade) were used as explanatory variables. Two models of multiple regression analysis were used. In model 1 , all variables tested in the correlation study, except the BODE index, were included. In model 2, the BODE index replaced $\mathrm{BMI}, \mathrm{FEV}_{1}, \mathrm{MMRC}$ grade and 6MWT. Due to the high colinearity between $\mathrm{BDI}$ and MMRC scores ( $r$ $>0.60, P=0.024)$, they were alternatively included in the regression model. Results of the multiple regression analysis are reported in terms of the estimated regression coefficient with corresponding confidence intervals. Values of $P<0.05$ were considered to be statistically significant. Statistical analysis was performed using the Sigma Stat statistical software (version 2.03, SPSS, Inc., USA).

\section{Results}

Patient characteristics are shown in Table 1. The degree of COPD was classified as very severe in 25 patients $(25.3 \%)$, as severe in 17 (17.2\%), as moderate in $37(37.3 \%)$ and as mild in 20 (20.2\%). Mean age was $64.2 \pm 9.2$ years, and mean $\mathrm{FEV}_{1}$ was $60.4 \pm 25.2 \%$ of predicted. As shown in Table 1, mean BMI values were within the normal range; however, individual analyses showed that $15 \%$ of the patients presented BMI $<21 \mathrm{~kg} / \mathrm{m}^{2}$, and that $44 \%$ of them presented FFMI values lower than the minimum $\left(\leq 16 \mathrm{~kg} / \mathrm{m}^{2}\right.$ for men or $\leq 15 \mathrm{~kg} / \mathrm{m}^{2}$ for women). Patients with very severe COPD presented significantly lower $\mathrm{SpO}_{2}$, reduced exercise capacity (assessed using the 6MWT), and greater dyspnea sensation compared with mild COPD patients.

There was a significant correlation between AQ20 score and SGRQ total score $(r=0.76, \mathrm{P}<0.01)$. In addition, AQ20 score correlated significantly with each of the three SGRQ domains (symptoms: $r=0.66, P<0.001$; activities: $r=0.76, \mathrm{P}<0.001$; impact: $r=0.79, \mathrm{P}<0.001$ ). Furthermore, both SGRQ and AQ20 scores correlated significantly with BODE index, MMRC grade and BDI (Table 2 and Figure 1), FEV 1 and 6MWT distance (Table 2). Neither the Charlson index nor any of the body composi-

Table 1. Characteristics of the patients with chronic obstructive pulmonary disease (COPD) as a function of disease stage.

\begin{tabular}{|c|c|c|c|c|}
\hline Variables & $\begin{array}{l}\text { COPD I } \\
(N=20)\end{array}$ & $\begin{array}{l}\text { COPD II } \\
(\mathrm{N}=37)\end{array}$ & $\begin{array}{l}\text { COPD III } \\
(\mathrm{N}=17)\end{array}$ & $\begin{array}{c}\text { COPD IV } \\
(N=25)\end{array}$ \\
\hline Male/Female (N) & $18 / 2^{+}$ & $22 / 15$ & $12 / 5$ & $17 / 8$ \\
\hline Age (years) & $66 \pm 12$ & $63 \pm 8$ & $67 \pm 8$ & $63 \pm 10$ \\
\hline $\mathrm{FEV}_{1}$ (\% of predicted) & $98.7 \pm 20.8^{*}$ & $62.6 \pm 10.5^{\star *}$ & $41.9 \pm 7.5$ & $39.3 \pm 10.6$ \\
\hline $\mathrm{SpO}_{2}(\%)$ & $95.5 \pm 2.1^{\#}$ & $94.3 \pm 2.4$ & $94.5 \pm 2.2$ & $89.0 \pm 5.0$ \\
\hline Body mass index $\left(\mathrm{kg} / \mathrm{m}^{2}\right)$ & $26.2 \pm 4.6$ & $26.7 \pm 5.8$ & $25.5 \pm 4.6$ & $25.6 \pm 7.0$ \\
\hline Fat-free mass index $\left(\mathrm{kg} / \mathrm{m}^{2}\right)$ & $16.6 \pm 1.7^{\#}$ & $16.0 \pm 1.9$ & $16.0 \pm 2.6$ & $16.0 \pm 2.3$ \\
\hline 6-min walk test distance $(\mathrm{m})$ & $475 \pm 99^{\#}$ & $444 \pm 90$ & $444 \pm 68$ & $380 \pm 71$ \\
\hline MMRC dyspnea grade & $2.0(1.0-2.60)^{\#}$ & $2.0(2.0-2.5)$ & $2.0(2.0-3.0)$ & $3.0(2.0-4.0)$ \\
\hline Baseline dyspnea index & $2.5(2.0-3.3)^{\#}$ & $2.3(1.8-3.5)$ & $2.0(1.3-2.8)$ & $1.3(0.7-2.0)$ \\
\hline Charlson index & $3.0(1.0-9.0)$ & $3.0(1.0-5.0)$ & $4.0(2.0-9.0)$ & $3.0(1.0-6.0)$ \\
\hline
\end{tabular}

Data are reported as means $\pm \mathrm{SD}$ or as median (25-75\% interquartile range). $\mathrm{FEV}_{1}=$ forced expiratory volume in $1 \mathrm{~s} ; \mathrm{SpO}_{2}=$ peripheral oxygen saturation; MMRC = Modified Medical Research Council. ${ }^{+} \mathrm{P}<0.05$ vs COPD II; ${ }^{*} \mathrm{P}<0.05$ vs COPD II, III and IV; ${ }^{*} \mathrm{P}<$ 0.05 vs COPD I, III and IV; \#P $<0.05$ vs COPD IV (ANOVA).

Table 2. Spearman's rank correlation coefficients describing the relationships between quality of life questionnaire scores and physiological/outcome variables.

\begin{tabular}{lccccc}
\hline Variables & \multicolumn{5}{c}{ Quality of life scores } \\
\cline { 2 - 5 } & AQ20 & SGRQT & SGRQS & SGRQA & SGRQI \\
\hline FEV $_{1}(\%$ of predicted) & $-0.35^{* *}$ & $-0.38^{* *}$ & $-0.27^{* *}$ & $-0.45^{* *}$ & $-0.30^{* *}$ \\
$\mathrm{SpO}_{2}(\%)$ & $-0.38^{* *}$ & $-0.32^{* *}$ & $-0.24^{* *}$ & $-0.33^{* *}$ & $-0.33^{* *}$ \\
6MWD (m) & $-0.33^{* *}$ & $-0.32^{* *}$ & $-0.24^{*}$ & $-0.48^{* *}$ & $-0.23^{*}$ \\
MMRC & $0.57^{* *}$ & $0.56^{* *}$ & $0.44^{* *}$ & $0.64^{* *}$ & $0.53^{* *}$ \\
BDI & $-0.66^{* *}$ & $-0.72^{* *}$ & $-0.49^{* *}$ & $-0.78^{* *}$ & $-0.70^{* *}$ \\
BODE index & $0.52^{* *}$ & $0.54^{* *}$ & $0.40^{* *}$ & $0.66^{* *}$ & $0.51^{* *}$ \\
\hline
\end{tabular}

$\mathrm{FEV}_{1}=$ forced expiratory volume in $1 \mathrm{~s} ; \mathrm{SpO}_{2}=$ peripheral oxygen saturation; $6 \mathrm{MWD}=6$ min walk test distance; $\mathrm{MMRC}=$ Modified Medical Research Council scale; $\mathrm{BDI}=$ baseline dyspnea index; BODE index = body mass index/airflow obstruction/dyspnea/ exercise capacity; AQ20 = Airways Questionnaire 20; SGRQT = St. George's Respiratory Questionnaire total score; SGRQS = SGRQ symptom domain score; SGRQA = SGRQ activity domain score; SGRQI $=\mathrm{SGRQ}$ impact domain score. ${ }^{*} \mathrm{P}<0.05$; ${ }^{*} \mathrm{P}<0.001$. 

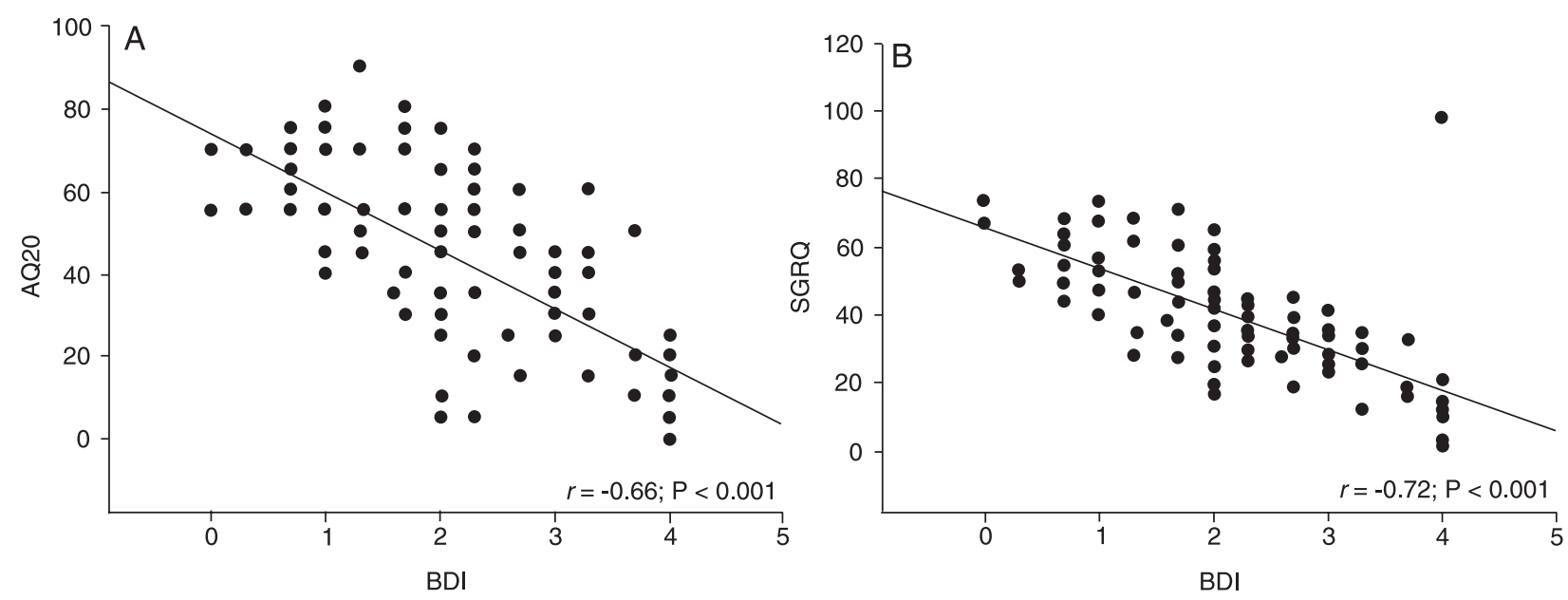

Figure 1. Relationship between baseline dyspnea index (BDI) and total scores of the Airways Questionnaire $20(A Q 20 ; A: N=99)$ and St. George's Respiratory Questionnaire (SGRQ; B: N = 99).

Table 3. Multiple regression analysis with the Airways Questionnaire 20 score as the dependent variable.

\begin{tabular}{lcccc}
\hline Variable & Coefficient & \multicolumn{2}{c}{$95 \%$ Confidence interval } & \multirow{2}{*}{ P value } \\
\cline { 3 - 4 } & & Lower limit & Upper limit & \\
\hline MMRC & 11.7 & 0.0 & 23.2 & $<0.001$ \\
BDI & -13.8 & -27.7 & 0.0 & $<0.001$ \\
\hline
\end{tabular}

The Modified Medical Research Council (MMRC) scale and baseline dyspnea index (BDI) were alternatively included in the regression model. Adjusted for gender, forced expiratory volume in the first second, 6-min walk test distance, and peripheral oxygen saturation. The BODE index was not included in this analysis.

Table 4. Multiple regression analysis with the St. George's Respiratory Questionnaire score as the dependent variable.

\begin{tabular}{lcccc}
\hline Variable & Coefficient & \multicolumn{2}{c}{$95 \%$ Confidence interval } & \multirow{2}{*}{ P value } \\
\cline { 3 - 4 } & & Lower limit & Upper limit & \\
\hline MMRC & 9.5 & 0.0 & 19.0 & $<0.001$ \\
BDI & -11.8 & -23.6 & 0.0 & $<0.001$ \\
\hline
\end{tabular}

The Modified Medical Research Council (MMRC) scale and baseline dyspnea index (BDI) were alternatively included in the regression model. Adjusted for gender, forced expiratory volume in the first second, 6-min walk test distance, and peripheral oxygen saturation. The BODE index was not included in this analysis.

tion variables correlated significantly with SGRQ or AQ20 scores.

In the multiple regression analyses of the potential predictors of health-related quality of life, dyspnea inten- sity, assessed using the BDI or MMRC scale (model 1) as well as using the BODE index (model 2), remained predictive of AQ20 and SGRQ scores. Dyspnea scores explained $38 \%$ of the AQ20 and $36 \%$ of the SGRQ variance. When the variables $\mathrm{FEV}_{1}, \mathrm{SpO}_{2}, 6 \mathrm{MWT}$ distance and MMRC grade were included in the model, the coefficient for the AQ20 was 11.7 (95\% confidence interval $=0.0$ to 23.2; $\mathrm{P}<0.001$ ) (Table 3), compared with 9.5 (95\% confidence interval $=0.0$ to $19.0 ; P<0.001)$ for the $S G R Q$ (Table 4). When the variables $\mathrm{FEV}_{1}, \mathrm{SpO}_{2}, 6 \mathrm{MWT}$ distance and $\mathrm{BDI}$ were included in the model, the coefficient for the AQ20 was -13.8 (95\% confidence interval $=-27.7$ to $0.0 ; P$ $<0.001$; Table 3), compared with -11.8 (95\% confidence interval $=-23.6$ to $0.0 ; \mathrm{P}<0.001$ ) for the SGRQ (Table 4). When $\mathrm{FEV}_{1}, 6 \mathrm{MWT}$ distance, MMRC grade and BMI were replaced by the BODE index, the coefficient for the AQ20 was 5.5 (95\% confidence interval $=0.0$ to $11.0 ; P<0.001)$, compared with 4.9 (95\% confidence interval $=0.0$ to $9.9 ; \mathrm{P}$ $<0.001)$ for the SGRQ.

\section{Discussion}

The main finding of this study was that the degree of dyspnea, as assessed using the BDI or MMRC scale, was the best predictor of AQ20 scores. The multidimensional (BODE) index, which incorporates BMI, FEV, $6 \mathrm{MWT}$ distance and MMRC grade, although presenting a lower predictive value than those obtained for each dyspnea measure in isolation, was also shown to be an independent predictor of AQ20 score. To our knowledge, this is the first time that a relationship between the BODE index and AQ20 scores has been established. In addition, our data show that, for the SGRQ, the predictor factors and the 
correlations identified between clinical variables and quality of life scores were very similar to the findings for AQ20.

Only two previous studies have evaluated the contribution of dyspnea sensation to AQ20 scores $(3,12)$. One evaluated the discriminatory power and responsiveness of the AQ20 compared with the SGRQ and Chronic Respiratory Questionnaire (CRQ), showing that dyspnea and anxiety accounted for $43 \%$ of the variance in AQ20 and CRQ scores (12). In a study performed to evaluate the linguistic and cultural translation of the AQ20 into Brazilian Portuguese, a statistical correlation between the BDI and AQ20 score was shown for the first time (3). The authors found that the strength of that correlation ranged from -0.36 to -0.64 .

The results of the present study showed that MMRC and $\mathrm{BDI}$ scores are responsible for approximately $38 \%$ of the AQ20 and 36\% of the SGRQ score variance. This is consistent with the results of studies showing that dyspnea perception can explain between 25 to $54 \%$ of the quality of life score variance in COPD patients $(10,27)$. In a recent study assessing dyspnea via the Oxygen Cost Diagram (OCD) and quality of life via the SGRQ in 83 patients with COPD (10), a significant correlation between OCD-assessed dyspnea and SGRQ score was detected ( $r=0.50$, $P<0.001)$. Using multiple regression analysis, the authors showed that dyspnea was the greatest contributing factor to the total SGRQ score, explaining $25 \%$ of the SGRQ total score. Using factor analysis, González et al. (27) found that dyspnea scale scores correlated with the scores for all dimensions of the $C R Q$. The authors used multivariate regression analysis and demonstrated that $\mathrm{BDI}$ was the best predictor of $C R Q$ score, explaining $54 \%$ of the quality of life variance in 40 emphysema patients. In addition, other studies have shown a strong relationship between SGRQ-assessed quality of life and dyspnea perception $(9,28)$.

In the present study, although the $\mathrm{FEV}_{1}$ and $6 \mathrm{MWT}$ distance presented a significant correlation with all domains of the SGRQ and AQ20 scores, in the multiple regression analysis, both variables were ruled out as predictive variables. It has been shown that $\mathrm{FEV}_{1}$ correlates weakly or not at all with SGRQ and AQ20 scores, and that, in multiple regression analyses, $\mathrm{FEV}_{1}$ is not identified as a predictor of health-related quality of life in COPD patients $(3,6,29,30)$. Some studies have shown a significant correlation between 6MWT distance and quality of life scores $(2,7,27,29)$. The results of a recent study confirm the relationship between $6 \mathrm{MWT}$ distance and SGRQ score
(10). However, consistent with our results, the authors of that study found that 6MWT distance was ruled out as a predictive variable in the multiple regression model.

In the present study, however, neither BMI nor FFMI correlated significantly with SGRQ or AQ20 scores. This is in agreement with a study showing no relationship between AQ20 scores and BMI (3). However, significant correlations between body composition attributes and SGRQ have been found in patients with COPD $(9,10)$. Assessing 50 patients with COPD, Shoup et al. (9) showed that underweight patients presented higher scores (indicating lower quality of life) in the activity and impact domains of the SGRQ, as well as higher total SGRQ scores, than did patients presenting normal body weight. The authors showed that low FFM was also associated with greater impairment of quality of life. However, when dyspnea was added to the model, neither weight nor FFM remained significantly related to quality of life. A recent study assessing 49 normal-weight and 34 underweight COPD patients showed that scores in all SGRQ domains, as well as total SGRQ scores, were significantly higher in the underweight group; in addition, BMI correlated significantly with all SGRQ scores except the SGRQ symptom score (10). However, stepwise multiple regression analysis used to identify variables that predict SGRQ total score showed that dyspnea assessed by OCD was the greatest contributing factor to the total SGRQ score (10).

The BODE index, which includes physiological variables other than dyspnea and has been shown to be superior to $\mathrm{FEV}_{1}$ alone in predicting risk of death among the COPD patients, is also a better predictor of hospitalization in these patients $(25,31)$. In the multivariate analyses conducted in the present study, the BODE index presented a lower coefficient than did MMRC grade or BDI. Nevertheless, it did correlate significantly with the quality of life questionnaire scores and was shown to be an independent predictor of health-related quality of life.

A limitation of the present study was that other factors known to be associated with impaired quality of life in COPD patients such as anxiety and depression were not assessed (32).

The relationships between AQ20 score and markers of disease severity are similar to those previously described for the SGRQ. Therefore, the AQ20, a simple and rapidly applied instrument to evaluate the general impact of disease, can be very useful when the time allotted for measurement of quality of life is limited. 


\section{References}

1. Leidy NK, Anton SF, Berzon RA, Margolis MK. An overview of health-related quality of life effects and outcomes in patients with COPD. Eur Respir Rev 2002; 12: 61-62.

2. Oga T, Nishimura K, Tsukino M, Sato S, Hajiro T. Analysis of the factors related to mortality in chronic obstructive pulmonary disease: role of exercise capacity and health status. Am J Respir Crit Care Med 2003; 167: 544-549.

3. Camelier A, Rosa FW, Jones PW, Jardim JR. Brazilian version of Airways Questionnaire 20: a reproducibility study and correlations in patients with COPD. Respir Med 2005; 99: 602-608.

4. Jones PW. St George's Respiratory Questionnaire: development, interpretation and use. Eur Respir Rev 2002; 12: 63-64.

5. Alemayehu B, Aubert RE, Feifer RA, Paul LD. Comparative analysis of two quality-of-life instruments for patients with chronic obstructive pulmonary disease. Value Health 2002; 5: 437-442.

6. Hajiro T, Nishimura K, Tsukino M, Ikeda A, Oga T, Izumi T. A comparison of the level of dyspnea vs disease severity in indicating the health-related quality of life of patients with COPD. Chest 1999; 116: 1632-1637.

7. Ketelaars CA, Schlosser MA, Mostert R, Huyer Abu-Saad $\mathrm{H}$, Halfens RJ, Wouters EF. Determinants of health-related quality of life in patients with chronic obstructive pulmonary disease. Thorax 1996; 51: 39-43.

8. Mostert R, Goris A, Weling-Scheepers C, Wouters EF, Schols AM. Tissue depletion and health related quality of life in patients with chronic obstructive pulmonary disease. Respir Med 2000; 94: 859-867.

9. Shoup R, Dalsky G, Warner S, Davies M, Connors M, Khan $M$, et al. Body composition and health-related quality of life in patients with obstructive airways disease. Eur Respir $J$ 1997; 10: 1576-1580.

10. Katsura H, Yamada K, Kida K. Both generic and disease specific health-related quality of life are deteriorated in patients with underweight COPD. Respir Med 2005; 99: 624630.

11. Sant'Anna CA, Stelmach R, Zanetti Feltrin MI, Filho WJ, Chiba T, Cukier A. Evaluation of health-related quality of life in low-income patients with COPD receiving long-term oxygen therapy. Chest 2003; 123: 136-141.

12. Hajiro $T$, Nishimura $K$, Jones $P W$, Tsukino $M$, Ikeda $A$, Koyama $\mathrm{H}$, et al. A novel, short, and simple questionnaire to measure health-related quality of life in patients with chronic obstructive pulmonary disease. Am J Respir Crit Care Med 1999; 159: 1874-1878.

13. Fabbri LM, Hurd SS. Global strategy for the diagnosis, management and prevention of COPD: 2003 update. Eur Respir J 2003; 22: 1-2.

14. Standardization of spirometry - 1987 update. Statement of the American Thoracic Society. Am Rev Respir Dis 1987; 136: $1285-1298$.

15. Knudson RJ, Lebowitz MD, Holberg CJ, Burrows B. Changes in the normal maximal expiratory flow-volume curve with growth and aging. Am Rev Respir Dis 1983; 127: 725-734.
16. Kyle UG, Bosaeus I, De Lorenzo AD, Deurenberg P, Elia M, Manuel GJ, et al. Bioelectrical impedance analysis - part II: utilization in clinical practice. Clin Nutr 2004; 23: 1430-1453.

17. Kyle UG, Pichard C, Rochat T, Slosman DO, Fitting JW, Thiebaud D. New bioelectrical impedance formula for patients with respiratory insufficiency: comparison to dualenergy X-ray absorptiometry. Eur Respir J 1998; 12: 960966.

18. Steiner MC, Barton RL, Singh SJ, Morgan MD. Bedside methods versus dual energy X-ray absorptiometry for body composition measurement in COPD. Eur Respir J 2002; 19: 626-631.

19. Souza TC, Jardim JR, Jones PW. Validação do questionário do hospital Saint George na doença respiratória (SGRQ) em pacientes portadores de doença pulmonar obstrutiva crônica no Brasil. J Pneumol 2000; 26: 119-125.

20. Mahler DA, Weinberg DH, Wells CK, Feinstein AR. The measurement of dyspnea. Contents, interobserver agreement, and physiologic correlates of two new clinical indexes. Chest 1984; 85: 751-758.

21. Martinez JAB, Padua Al. Dispnéia: novos conhecimentos sobre um velho problema. In: Terra Filho M, Fernandes ALG, Stirbulov R (Editors), Pneumologia: atualização e reciclagem. Vol. IV. São Paulo: Vivali; 2001. p 1-12.

22. Mahler DA, Wells CK. Evaluation of clinical methods for rating dyspnea. Chest 1988; 93: 580-586.

23. Jardim JR, Oliveira JA, Nascimento O. II Consenso Brasileiro de DPOC. J Bras Pneumol 2004; 30: S1-S42.

24. ATS statement: guidelines for the six-minute walk test. $A m$ J Respir Crit Care Med 2002; 166: 111-117.

25. Celli BR, Cote CG, Marin JM, Casanova C, Montes de OM, Mendez RA, et al. The body-mass index, airflow obstruction, dyspnea, and exercise capacity index in chronic obstructive pulmonary disease. $N$ Engl J Med 2004; 350: 1005-1012.

26. Charlson M, Szatrowski TP, Peterson J, Gold J. Validation of a combined comorbidity index. J Clin Epidemiol 1994; 47: 1245-1251.

27. González E, Herrejon A, Inchaurraga I, Blanquer R. Determinants of health-related quality of life in patients with pulmonary emphysema. Respir Med 2005; 99: 638-644.

28. Hajiro T, Nishimura K, Tsukino M, Ikeda A, Oga T. Stages of disease severity and factors that affect the health status of patients with chronic obstructive pulmonary disease. Respir Med 2000; 94: 841-846.

29. Dourado VZ, Antunes LCO, Carvalho LR, Godoy I. Influência de características gerais na qualidade de vida em pacientes com doença pulmonar obstrutiva crônica. J Bras Pneumol 2004; 30: 207-214.

30. Renwick DS, Connolly MJ. Impact of obstructive airways disease on quality of life in older adults. Thorax 1996; 51: 520-525.

31. Ong KC, Earnest A, Lu SJ. A multidimensional grading system (BODE index) as predictor of hospitalization for COPD. Chest 2005; 128: 3810-3816.

32. Sanjuas $C$. Dyspnea and quality of life in chronic obstructive pulmonary disease. Arch Bronconeumol 2002; 38: 485-488. 